\title{
The problem of rational use and protection of agricultural land
}

\author{
Ekaterina Khomutova ${ }^{1, *}$ \\ ${ }^{1}$ Institute of Service and Entrepreneurship (branch) of DSTU in Shakhty, 147, Shevchenko str., \\ Shakhty city, Rostov region, 346500, Russia
}

\begin{abstract}
In this article we consider the current issues of effective use of agricultural land of the indicators of the state of the country's land fund, the development of private ownership of agricultural land are given. The problems in the field of rational use and protection of agricultural land are shown.
\end{abstract}

\section{Introduction}

Currently, the fundamental land management activities carried out in the Russian Federation are planning and organizing the rational use of land and its protection. Rational use of agricultural land is the use of land, without reducing or reducing the area of farmland, guaranteed by the average productivity of land. In accordance with the Land Code of the Russian Federation, "agricultural land is land located outside the borders of settlements, provided for the needs of agriculture or intended for these purposes." Such lands are the basic means of production in agriculture, have a characteristic legal regime and are subject to special protection, in terms of preserving their area, preventing the formation of adverse processes, as well as improving soil fertility. Considering the period 2010-2020, we can say that the area of agricultural land has decreased by almost a third. The share of these lands in the structure of the land fund also decreased (from $37.3 \%$ to $23.6 \%$ ) $[1,2,3]$.

Attention is also drawn to the fact that in recent years the area of such land has significantly decreased. Food production is the most basic and tangible example of humans' dependence on nature. From Paleolithic hunter-gatherers, who relied on direct harvest from nature, to contemporary complex societies that rely on agriculture and livestock, human survival ultimately depends on what the land provides. An ever growing population and demand for food are putting unprecedented pressure on the environment. Increased food consumption necessitates agriculture expansion; however, the last IPBES report highlights the role of agricultural land expansion as the main threat to biodiversity loss, mediated by the fragmentation and degradation of habitats $[5,6,7]$.

Degradation of the natural environment brings societal and economic consequences for human populations, as it can result in decreasing agricultural yields and public health issues. Conservation of biodiversity and natural spaces are often considered secondary objectives when compared to food security, but biodiversity and ecosystem services play an integral role in maintaining food supply. Agricultural productivity is strongly dependent on

*Corresponding author: shpigunova96@mail.ru 
ecosystem services, such as pollination, nutrient cycling and pest control, that surrounding natural spaces provide.

Therefore, conservation goals should not be seen as opposed to agricultural production or human well-being, as natural land is essential to provisioning services. Allying natural and agricultural lands is the key to achieve sustainability and avoid a potential socio-ecological collapse. The introduction of agriculture permitted the apparition of the first permanent human settlements. However, Neolithic settlements quickly became heavily reliant on the agricultural system and, as a result, when environmental disasters struck, the food supply and the population suffered. In some cases, as much as $60 \%$ of the population was lost due to failed crops.

Over time technological developments made it possible for human societies to adopt more intense forms of agriculture, which increased resource production and food security. Agricultural production enabled the population to grow and allowed the development of complex societies via social differentiation and territorial expansion. This drive to increase agricultural production, however led to deforestation, excessive freshwater use, soil biodiversity loss, altered nutrient and water cycles, decreased pollinator abundance, and increased vulnerability to environmental change, all of which can have deleterious effects on agricultural production $[8,9]$.

Agriculture is thus dependent on the natural environment, but it also heavily transforms this environment. The aim of future societies is to have agriculture improve social welfare, but how to achieve this, while limiting environmental degradation, is a major unknown. Agriculture has been responsible for both the rise and fall of societies.

Historical examples of societal collapse are geographically diversed and have occurred over various time scales. Several social, political and economical mechanisms have been proposed to explain such collapses. However, for a number of them, the roots of societal decline can be traced back to ecological problems caused by resource over-exploitation and poor agricultural land management.

The Mayan and the Anasazi collapses are two classic examples. In both cases, collapse is thought to have resulted from feedbacks between population growth and agricultural expansion and intensification, which led to greater environmental degradation and made the food production system unviable. Food scarcity sows the seeds of economic trouble, social unease and political instability, which trap societies in positive feedback loop leading to collapse.

\section{Methodology}

Comparative law research. This method was used to compare and characterize the PFE legal status: individual entrepreneur and legal entity, as well as identifying their specific advantages over other legal forms; Legal norms analysis method. An analysis of the current legislation provisions allows us to identify the meaning of a legal norm and determine the degree of its influence on public relations development.

The legal norms interpretation method. The historical and political method of interpretation helps to reveal the meaning of a legal norm, appealing to the history of its adoption, the goals and motives that determined its introduction into the system of legal regulation.Judicial and law enforcement analysis method practice. This method is based on the decisions analysis of various instances of the law enforcement agencies in relation to cases with PFE participants. 


\section{Results of the research}

Disturbed lands have low economic value, critically pollute the atmosphere with various dangerous chemicals, and have a harmful impact on the living conditions and development of people. Unfavorable processes lead to a decrease in the potential of land resources and, as a result, the volume of agricultural production, which creates a threat to the population of the country. The necessary means for prevention is the rational use of land on the basis of the formation of the economic basis of the economic activity of people. This is especially important in modern economic conditions, when the shortage of production resources is accompanied by a decrease in soil fertility.

The effectiveness of nature management is determined by the restoration of the state of the external environment and the widespread reproduction of natural resources through restoration, rehabilitation and other measures. The efficiency of land use determines the rationality of its use. Rational use of land involves its use taking into account the general interests of the population, provides the most economically profitable material use of useful resources in the production process, as well as optimal interaction with the environment and legal protection of the soil resources of our state. Rational and efficient use of agricultural land is important for every state [10,11].

The Russian Federation is no exception, our country has such unique and significant resources. The most important task of our state is to use it as much as possible and of high quality in order to develop our agriculture, in order to produce products that feed the population with the highest quality, environmentally friendly products at affordable prices. In recent years, there has been a steady trend of deterioration in the quality of soil resources, in particular, this is due to agricultural and man-made loads on the land, which increase every year. More than $55 \%$ of the irrigated land needs a complete reformation. Another negative trend is the activation of the second process of soil salinization.

The transformation of the soil has led to significant changes in the method of land redistribution and in the conditions for its implementation. The ongoing transformations have led to the destruction of the resource potential of the agricultural sector and, as a result, to a sharp decline in production. Every agricultural enterprise uses chemical components in the cultivation of the soil or the plants growing on it. A side effect of the treatment is the contamination of the soil with toxic chemicals. These include, first of all, pesticides-means used to destroy pests, weeds and pathogens of cultivated vegetable crops. These chemicals do not decompose and are stored in the soil. The lack of an effective economic mechanism for land management and use and, as a result, the slow pace of implementation of environmental and conservation technologies lead to a shortage and degradation of land resources. About a third of the world's soils are considered degraded [12,13].

The state of the soil in Russia also leaves much to be desired, but scientists do not lose enthusiasm and offer new ways to solve the problem of the Earth is our main source of energy on the surface, that is, in our country, the earth is the source of 95 percent of the land. It is very important to take measures to prevent this process, because the soil is already turning into a salt marsh with chemical and radioactive elements. Ten-year studies of the Agrochemical Service show that in all types of soils, the level of humus has decreased to 20 $\%$. And this is only in the last decades. If this continues, the wealth of the soil will be exhausted from it for centuries. Some experts note that after independence, farmers did not have the opportunity to pay due attention to soil fertility. Much of the land was abandoned. In order to restore soil fertility, it is necessary to invest a large amount of money in the use of fertilizers, because the loss of indicators of the nutritional value of the land affects the yield of the fields. According to the latest official data, 68\% of Russia's land resources are subject to various types of degradation, including soil erosion, and, accordingly, are not used in agricultural production. There are many examples of areas where a third of the land is 
subject to secondary and tertiary pollution. Continuous cultivation of monocultures also negatively affects the sustainability of land resources.

The root negative processes are:

- erosion;

- deflation;

- waterlogging;

- salinization;

- desertification;

- flooding;

- overgrowth of agricultural land with shrubs and small woodlands;

- and other processes leading to the loss of agricultural land fertility and their

According to the report "On the State and Environmental Protection of the Russian Federation in 2020", about $82 \%$ of agricultural land, or 190 million hectares, is subject to degradation, especially erosion. Water erosion affects $19 \%$ of the area of agricultural land, wind-9 $\%$, waterlogged and wetlands occupy $14.4 \%$, saline and saline- $23.4 \%$ of agricultural land. Agricultural land is seized for non-agricultural purposes, mainly for construction and mining. As a result, there is a violation of agricultural land by mining.

The exploitation of agricultural and fertile land should not deplete the soil, but contribute to the preservation and multiplication of land resources of the agro-industrial complex. Land use should be close to the most natural order maintaining the balance of arable land and hayfields; forest belts and other protective plantings should be preserved and restored; reducing industrial and non-agricultural land use [14].

\section{Discussion of results}

Agricultural lands are important industrial objects of vital activity, a source of economic and environmental well-being of the country, so it is important to use them efficiently and efficiently. The aim of the study is to find ways to improve all indicators of land use and to put forward proposals for the development of the most rational structure of agricultural land in each farm. If we do not consider this a global problem, intensive land use will lead to huge damage to the natural environment [15].

Underestimation of the agroecological state of the soil and the absolutization of the technogenic principle of industrial development worsen the quality of the soil. All this contributes to the growth of negative trends in the health of the population. At the heart of these problems is the development of biologically adapted ways to manage agricultural entities. As of January 1, 2020, the area of agricultural land was 7073.4 thousand square meters. ha (Table 1). This category includes land granted to various agricultural enterprises and organizations (partnerships and societies, cooperatives, state and municipal unitary enterprises, research institutions). It also includes land plots provided to citizens for conducting peasant (farm) farming, personal subsidiary farming, gardening, gardening, animal husbandry, haymaking, etc. 


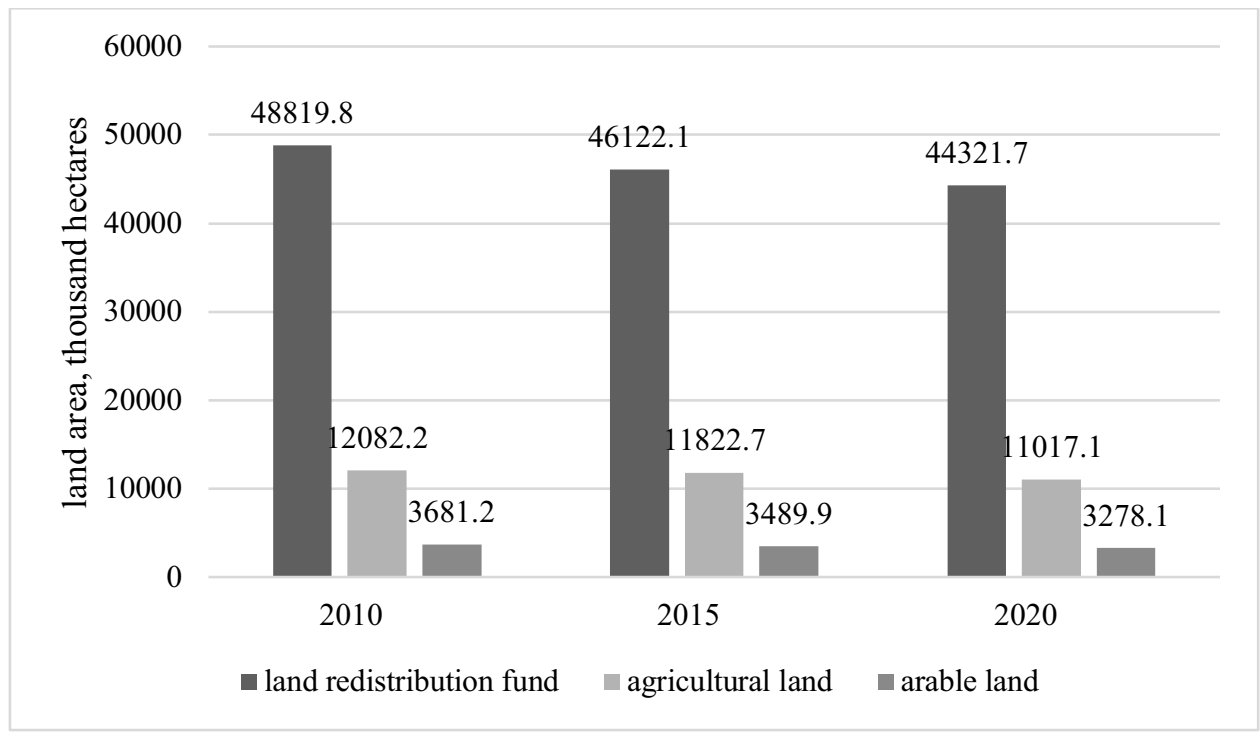

Fig. 1. Land area.

Unfortunately, today there are a number of factors that destroy the surface of agricultural land and seriously change the natural landscape. These factors are:

- industrial development;

- urban planning ;

- water intake structures and water sources.

Approximately $80 \%$ of agricultural lands suffer from moderate to severe erosionъ. Annual soil eroded from agriculture lands is 75 billion tonnes, which is estimated a loss cost of US \$400 billion per year. Both land use and management have great impact on soil erosion attributed as many as $65 \%$ of changes in soil erosion in watershed to land use. Land use could change the soil loss patterns, resulting in different soil erosion intensity. In the northeastern China, water erosion on slope farmlands is the main factor that contributes to soil loss.

The soil erosion of agricultural land reduces when the land use type changes from arable land to orchard. Land managements, such as drainage measure, soil improvement, tillage management and surface mulching, are used to prevent farmland erosion by decreasing erodibility and runoff efficiency on bare or low groundcover soils. For instance, the run off and erosion on cropland with straw coverage decrease obviously in contrast with cropland with bare soil, which have garnered concern worldwide. Tillage management practices such cross-slope intercropping and slope intercropping could prevent more than $60 \%$ of the total erosion amount comparing to sloped cropland. Interplanting crops to increase land coverage is considered an effective measure to prevent soil erosion in cropland.

\section{Conclusions}

In conclusion, we note that the degradation is increasing due to the practice of irrational use of agricultural land. In the context of the growing importance of soil as a factor of production, these trends are very unfavorable. A rational approach to land use is beneficial to agricultural producers both economically and socially, as it allows them to achieve long-term and sustainable results through the scientific use of qualitatively protected and constantly updated land resources. Agricultural enterprises should take into account the environmental benefits 
of land use when building production facilities. This will ultimately affect the efficiency of land use.

The method of rational use of land by agricultural producers is economically and socially beneficial, as it provides long-term and stable results through the use of qualitatively preserved and constantly updated land resources. Summing up, we note that at present, a rational approach to the use of agricultural land is socially and economically profitable, due to the scientifically based use of qualitatively preserved and constantly updated land resources. Agricultural enterprises should take into account the ecological efficiency of land use as an essential element in the construction of production activities. This will ultimately affect the efficiency of land use.

\section{References}

1. J. Bongaarts, Popul. Dev. Rev. 45(3), 680-681 (2019)

2. A.P. Jacobson, J. Riggio, A.M. Tait, J.E.M. Baillie, Sci. Rep. 9(1), 1-13 (2019)

3. J. Nowosad, T.F. Stepinski, Geophys. Res. Lett. 46(23), 13845-13852 (2019)

4. M.G.E. Mitchell, E.M. Bennett, A. Gonzalez, J. Appl. Ecol. 51(4), 909-918 (2014)

5. V. Cazalis, M. Loreau, K. Henderson, Sci. Total Environ. 634, 1463-1474 (2018)

6. Close S.S. Downey, W.R. Haas, S.J. Shennan, Proc. Natl. Acad. Sci. 113(35), 9751-9756 (2016)

7. M.A. Tsiafouli, E. Thébault, S.P. Sgardelis, et al., Glob. Chang Biol. 21(2), 973-985 (2015)

8. SG.S. Cumming, G.D. Peterson, Trends Ecol. Evolut. 32(9), 695-713 (2017)

9. G.S. Cumming, G.D. Peterson, Trends Ecol. Evolut. 32(9), 695-713 (2017)

10. J. McGinlay, D.J.G. Gowing, J. Budds, Environmental Science \& Policy 69, 39-49 (2017)

11. S. Li, X. Li, J. Geogr. Sci. 27(9), 1123-1150 (2017)

12. S. Estel, T. Kuemmerle, C. Alcántara, C. Levers, A. Prishchepov, P. Hostert, Remote Sensing of Environment 163, 312-325 (2015)

13. C.F. Dormann, J. Elith, S. Bacher et al., Ecography 36(1), 27-46 (2013)

14. P. Meyfroidt, E.F. Lambin, K.-H. Erb, T.W. Hertel, Curr. Opin. Environ. Sustain. 5, 438444 (2013) 